15 Anonymous. Lowering blood pressure without drugs. Lancet 1980;ii: 459-61.

16 Kempner $W$. Treatment of hypertensive vascular disease with rice diet. Am $\mathcal{F}$ Med 1948;4:545-77.

17 Medical Research Council. The rice diet in the treatment of hypertension. Lancet 1950 ;ii:509-13.

${ }^{18}$ Kawasaki T, Delea CS, Bartter FC, Smith H. The effect of high-sodium and low-sodium intakes on blood pressure and other related variables in human subjects with idiopathic hypertension. Am 7 Med 1978;64: 193-8.

19 Van Brummelen P, Schalekamp M, De Graeff J. Influence of sodium intake on hydrochlorothiazide-induced changes in blood pressure, serum electrolytes, renin and aldosterone in essential hypertension. Acta Med Scand $1978 ; 204: 151-7$.
${ }^{20}$ Parijs J, Joossens JV, van der Linden L, Verstreken G, Amery AKPC. Moderate sodium restriction and diuretics in the treatment of hypertension. Am Heart $\mathcal{F} 1973 ; 85: 22-34$

${ }^{21}$ Morgan T, Adam W, Gillies A, Wilson M, Morgan G, Carney S. Hypertension treated by salt restriction. Lancet $1978 ; \mathrm{i}: 227-30$.

${ }^{22}$ Beevers DG. Blood pressures that fall on rechecking. $\mathrm{Br}$ Med $\mathcal{f} 1982$; 284:71.

${ }^{23}$ Parfrey PS, Markandu ND, Roulston JE, Jones BE, Jones JC, MacGregor GA. Relation between arterial pressure, dietary sodium intake and renin system in essential hypertension. Br Med F $1981 ; 283: 94-7$.

24 Beard TC, Cooke HM, Gray WR, Barge R. Randomised controlled trial of a no-added-sodium diet for mild hypertension. Lancet 1982 ;ii :455-8.

(Accepted 29 November 1982)

\title{
Method of healing diabetic forefoot ulcers
}

\author{
J P POLLARD， L P LE QUESNE
}

\begin{abstract}
Six diabetic patients with neuropathic ulceration of the sole of the foot (seven feet, eight ulcers) were treated by the application of a below knee walking plaster with a rubber rocker. All the ulcers healed with this treatment, greatly reducing the usual period of hospital inpatient stay. After healing, study of the forces acting on the sole of the foot showed that these ulcers occur at the site of maximal horizontal shear force and confirmed that they occur at the site of maximal vertical force.

This treatment is highly effective for neuropathic ulcers of the sole not affecting bone or complicated by deep sepsis. There may be a high rate of recurrence, however, reflecting inadequacy of methods of protecting damaged neuropathic feet.
\end{abstract}

\section{Introduction}

It has long been thought that mechanical factors play a part in diabetic neuropathic ulcers of the sole. A recent study ${ }^{1}$ showed clearly that these ulcers occur at the site of maximum pressure (vertical force), and although there are certainly other factors in their formation, the site of the ulcer is clearly determined by mechanical factors.

We have shown that both the vertical and shearing (longitudinal and transverse) components of force acting on the foot during walking are greatly modified by the type of footwear, and in particular that a below knee plaster cast with a rubber rocker greatly reduces all three components of force. ${ }^{2}$ This suggested that it might be possible to heal diabetic neuropathic ulcers in such a cast, and we therefore report the results of this method of treatment. We also give the results of measuring the components of force after the ulcers had been healed.

Middlesex Hospital, London W1N 8AA

J P POLLARD, FRCS, research assistant (now consultant orthopaedic surgeon, Horton Hospital, Banbury)

L P LE QUESNE, DM, FRCS, professor, department of surgical studies

\section{Method}

TREATMENT OF ULCERS

For treatment in a plaster cast the ulcer had to be moderately clean with healthy granulation tissue and without excessive discharge. We achieved this by bed rest, paring the overhanging edges of the ulcer, and on occasions antibiotics for a short period. Deep sepsis or osteomyelitis of the metatarsal head rendered the ulcer unsuitable for treatment by this method.

A conventional below knee plaster cast with a rubber rocker for weight bearing was then applied. On account of the sensory peripheral neuropathy great care was taken to apply adequate padding, and an extra layer of self adhesive foam rubber was applied around the malleoli. The forward projection of the cast was restricted to the level of the mid-shaft of the proximal phalanges of the toes, so that by dorsiflexion of the toes the dressing could be withdrawn, the ulcer inspected, and a new dressing inserted. Re-dressing was usually required daily, the dressing used being non-adhesive, presterilised Melolin (Smith and Nephew Ltd). The plaster was retained for two weeks after healing to allow some consolidation to occur.

In practice the plaster casts required changing after three or four weeks because of softening or soiling from discharge, or to allay anxiety about the state of the neuropathic foot in a plaster cast; however, no troublesome pressure problems were encountered.

\section{ANALYSIS OF FORCES}

Once the ulcer was healed it was possible to analyse the forces under the forefoot, as described. ${ }^{2} 3$ The three components of force (vertical, longitudinal shear, transverse shear) were analysed separately in different footwear using transducers attached to the sole of the foot with double sided adhesive tape. Transducers were located under the hallux, under the first, second and third, and fourth and fifth metatarsal heads, and under the midpoint of the heel.

Recordings were made with the patients walking barefoot, in a pair of conventional leather shoes, in the same shoes with a single $6 \mathrm{~mm}$ layer of low density Plastazote as an insole, in a pair of extra lepth surgical shoes (Drushoe) designed to accommodate two $6 \mathrm{~mm}$ layers of Plastazote (one of medium density, one of low density), and in a below knee plaster cast.

\section{PATIENTS}

Seven ulcerated feet in six diabetic patients (age range 27-75 years; mean 47 ) were treated by the methods described. All patients had severe peripheral neuropathy affecting the legs with absent or severely impaired sensation to light touch and pain. In all except one patient both peripheral pulses were palpable at the ankle; in the oldest patient 
the dorsalis pedis pulses were not palpable. In five feet the ulcer was under the first metatarsal head, one of these patients having a second ulcer under the head of the fifth metatarsal, and in two feet the ulcer was under the fourth metatarsal head.

Six healed feet in five patients were available for analysis of the forces under the foot. One foot relapsed quickly after removal of the plaster owing to previously unrecognised osteomyelitis of the metatarsal head, making testing impossible.

\section{Results}

TREATMENT OF ULCERS

The ulcers under all seven feet were healed successfully by the plaster cast regimen. In each patient a short initial period of between two days and two weeks of inpatient treatment was required to clean the ulcer, and the healing time in plaster varied from three to eight weeks (mean 5.4 weeks).

After healing all patients were supplied with Drushoes with standard Plastazote insoles. Excluding the foot which relapsed early owing to osteomyelitis developing during the period in the plaster cast, there were six successfully treated feet. Three of these feet remained healed for between four and 12 months (mean 8.5 months), but the ulcer recurred in the other three feet; in each case this occurred within two months of the end of plaster treatment. Two of these patients required a ray amputation after osteomyelitis developed, and one was healed successfully with a further period in a plaster cast.

\section{ANALYSIS OF FORCES}

The study showed that in each patient the neuropathic ulcer occurred at the site not only of the highest vertical force but also of maximum longitudinal shear force; this applied whether walking barefoot or in any of the shoes tested. The different types of footwear affected the shear forces in the same way as in normal subjects. ${ }^{2}$

\section{Discussion}

The conventional treatment of diabetic neuropathic ulcers of the sole not affecting the underlying bone is bed rest, with minimum surgical debridement and sometimes a course of antibiotics. On this regimen healing is almost always obtained, but this often entails a long period in hospital. Based on the observation that a below knee plaster cast greatly reduces the three components of force acting on the foot, a trial was carried out to see if healing could be obtained by the use of such a plaster. This study shows that this is, in fact, the case, all seven ulcers so treated healing successfully in three to eight weeks. Although healing occurred no quicker, and possibly more slowly, than with bed rest, the treatment has the advantage of greatly reducing the period of bed rest and inpatient treatment, allowing the patient to continue his normal activities during healing. The treatment is not appropriate if bone is affected, when some form of excisional surgery is required, usually ray amputation. The necessity for this was illustrated by one patient in this series, in whom the bone disease was not detected, with consequent prompt reopening of the ulcer after apparent healing.

Once the ulcer is healed an entirely new problem arisesnamely, to prevent recurrence. Given that the same mechanical forces are still operating it is not surprising that recurrence is common. The high recurrence rate in this small series is but a further illustration of the inadequacy of current methods of protecting these damaged, neuropathic feet.

Diabetic neuropathic ulcers have been shown to occur at the site of maximal vertical loading. ${ }^{1}$ This study shows that they also occur at the site of maximal horizontal shear, though it does not in any way indicate which of these two forces is the most important in determining the site of the ulcer.

While undertaking this study one of us (JPP) was supported by a grant from the Department of Health and Social Security.

Requests for reprints should be sent to Professor Le Quesne.

\section{References}

${ }^{1}$ Ctercteko GC, Dhanendran M, Hutton WC, Le Quesne LP. Vertical forces acting on the feet of diabetic patients with neuropathic ulceration Br f Surg 1981;68:609-14.

${ }^{2}$ Pollard JP, Le Quesne LP, Tappin JW. Forces under the foot. $\mathcal{F}$ Biomed Eng $1983 ; 5: 37-40$.

3 Tappin JW, Pollard J, Beckett EA. Method of measuring "shearing" forces on the sole of the foot. Clinical Physics and Physiological Measurement $1980 ; \mathrm{i}: 83-5$.

(Accepted 1 December 1982)
FEVERFEW OR FEATHERFEW. Common Featherfew has large, fresh, green leaves, much torn or cut on the edges. The stalks are hard and round, set with many such like leaves, but smaller, and at the tops stand many single flowers, upon small foot stalks, consisting of many small white leaves standing round about a yellow thrum in the middle. The root is somewhat hard and short, with many strong fibres about it. The scent of the whole plant is very strong, and the taste is very bitter. This grows wild in many places of the land, but is for the most part nourished in gardens. It flowers in the months of June and July.

Venus commands this herb, and has commended it to succour her sisters (women) and to be a general strengthener of their wombs, and remedy such infirmities as a careless mid-wife hath there caused: if they will but be pleased to make use of her herb boiled in white wine, and drink the decoction; it cleanses the womb, expels the after-birth, and doth a woman all the good she can desire of an herb. And if any grumble because they cannot get the herb in winter, tell them, if they please, they may make a syrup of it in summer; it is chiefly used for the disease of the mother, whether it be the strangling or rising of the mother, or hardness, or inflammation of the same, applied outwardly thereunto. Or a decoction of the flowers in wine, with a little Nutmeg or Mace put therein, and drank often in a day, is an approved remedy to bring down women's courses speedily, and helps to expel the dead birth and after-birth. For a woman to sit over the hot fumes of the decoction of the herb made in water or wine, is effectual for the same; and in some cases to apply the boiled herb warm to the privy parts. The decoction thereof made with some sugar, or honey put thereto, is used by many with good success to help the cough and stuffing of the chest, by colds, as also to cleanse the reins and bladder, and helps to expel the stone in them. The powder of the herb taken in wine, with some Oxymel, purges both choler and phlegm, and is available for those that are short winded, and are troubled with melancholy and heaviness, or sadness of spirits. It is very effectual for all pains in the head coming of a cold cause, the herb being bruised and applied to the crown of the head: As also for the vertigo, that is a running or swimming in the head. The decoction thereof drank warm, and the herb bruised with a few corns of Bay salt, and applied to the wrists before the coming of the ague fits, doth take them away. The distilled water takes away freckles, and other spots and deformities in the face. The herb bruised and heated on a tile, with some wine to moisten it, or fried with a little wine and oil in a frying-pan, and applied warm outwardly to the places, helps the wind and cholic in the lower part of the belly. It is an especial remedy against opium taken too liberally. (Nicholas Culpeper (1616-54) The Complete Herbal, 1850.) 